\title{
Electronic Structure and Properties of the Group 4, 5, and 6 Highest Chlorides Including Elements 104, 105, and 106
}

\author{
V. Pershina* and B. Fricke \\ Theoretical Physics Department, University of Kassel, D-34132 Kassel, Germany
}

Received: January 21, 1994; In Final Form: April 27, $1994^{\circ}$

\begin{abstract}
Results of the Dirac-Slater discrete variational calculations for the group 4,5, and 6 highest chlorides including elements 104,105 , and 106 have shown that the groups are not identical with respect to trends in the electronic structure and bonding. The charge density distribution data show that notwithstanding the basic increase in covalency within the groups this increase diminishes in going from group 4 to group 6 . As a result, $\mathrm{E} 106 \mathrm{Cl}_{6}$ will be less stable toward thermal decomposition than $\mathrm{WCl}_{6}$, which is confirmed by an estimated low E106-Cl bond energy. $\Delta H_{\text {form }}$ equal to $-90.3 \pm 6 \mathrm{kcal} / \mathrm{mol}$ is obtained for $\mathrm{E} 106 \mathrm{Cl}_{6}$ in the gas phase, which is indicative of a very low stability of this compound. The stability of the maximum oxidation state is shown to decrease in the direction E104(+4) $>\mathrm{E} 105(+5)>\mathrm{E} 106(+6)$.
\end{abstract}

\section{Introduction}

A. Experimental Investigation. Identification of properties of the transactinides has been done by studying volatility of their highest halides: tetrachlorides ${ }^{1}$ of element $104, \mathrm{Rf}$, along with analogs $\mathrm{MCl}_{4}(\mathrm{M}=\mathrm{Zr}, \mathrm{Hf})$, and pentachlorides ${ }^{2}$ and pentabromides $^{3}$ of element $105, \mathrm{Ha}$, along with analogs $\mathrm{MCl}_{5}$ and $\mathrm{MBr}_{5}$ $(\mathrm{M}=\mathrm{Nb}, \mathrm{Ta})$. In a number of experiments ${ }^{1-3}$ the gas-phase chromatography technique has been applied to study the ability of these highest halides to pass through the chromatography column as a function of temperature. The temperature at $50 \%$ yield has been accepted as a measure of the volatility and correlated with the enthalpy of adsorption. A new series of experiments is presently under preparation to study the volatility of the group 6 (Mo, W, and element 106) halides and oxyhalides. ${ }^{4}$

Results of these experiments have shown that groups 4 and 5 are not identical with respect to the trends in the volatility of the halides; the tetrachloride of element 104 seems to be more volatile than the tetrachloride of $\mathrm{Hf}^{\mathrm{ib}}$ while the pentabromides of element 105 turned out to be less volatile than the pentabromides of $\mathrm{Nb}$ and $\mathrm{Ta}^{3}$ A reason for the latter case may be either formation of oxybromides or thermal decomposition. A big question now exists about group 6, where the situation is expected to be even more complex.

B. Basic Characteristics of Halides of the Transition Elements. Among all the halides of the second and third transition rows, fluorides are known to be most stable in the highest oxidation states. Chlorides, bromides, and iodides occur in lower oxidation states, and their stability (also to thermal decomposition) decreases in the direction $\mathrm{F}>\mathrm{Cl}>\mathrm{Br}>\mathrm{I}$. Volatility decreases in the same sequence, making measurements of physical properties for heavy halides very difficult. As a consequence, the amount of available experimental information decreases with increasing atomic number of the halide. Fluorides are also easier to prepare, and techniques for their synthesis are well developed. Nevertheless, using fluorine as a halogenating agent has some serious disadvantages. The resulting fluorides are reactive, sensitive to moisture, and difficult to handle. Reactivity and sensitivity to moisture decrease with increasing atomic number of the halide. Taking into account all these facts, the chlorides are, probably, the most appropriate species (in comparison with other halides) for studying volatility of the transactinide compounds.

Heats of formation ${ }^{5-8}$ of the chlorides of transition elements show clearly the characteristic trends in the stability of these compounds: (1) the chlorides of the $5 \mathrm{~d}$ elements are more stable

\footnotetext{
- Abstract published in Advance ACS Abstracts, June 1, 1994.
}

in high oxidation states, but the $4 \mathrm{~d}$ compounds are more stable in low oxidation states; (2) toward the right of the periodic table the stability of the maximum oxidation state of the elements in chlorides falls rapidly. The maximum oxidation state of Mo is not stable as the chloride. (For no element beyond group 6 is the maximum oxidation state attainable as a chloride; for example, $\mathrm{ReF}_{7}$ has been obtained but not $\mathrm{ReCl}_{7}$.)

Among the highest chlorides, tetrachlorides of $\mathrm{Zr}$ and $\mathrm{Hf}$ are stable volatile species, having a regular tetrahedral coordination of the $\mathrm{Cl}$ atoms about the central metal atom ( $T_{\mathrm{d}}$ symmetry). ${ }^{9}$ Group 5 pentachlorides, $\mathrm{NbCl}_{5}$ and $\mathrm{TaCl}_{5}$, are also stable, rather volatile compounds, having a geometrical configuration of a trigonal bipyramid of $D_{3 h}$ symmetry. ${ }^{10}$

The only known $n^{5,9}$ relatively stable highest chloride in group 6 is $\mathrm{WCl}_{6}$, which decomposes at the boiling point of $346^{\circ} \mathrm{C}$. There are some contradictory data ${ }^{5,6 b, c}$ about the existence of $\mathrm{MoCl}_{6}$, but the estimates of the enthalpy of formation of $\mathrm{MoCl}_{6}$ (s) and $\mathrm{MoCl}_{6}(\mathrm{~g})$ of -132.15 and $-110.28 \mathrm{kcal} / \mathrm{mol}$, respectively, correspond to this compound being barely stable at room temperature in an atmosphere of chlorine. In the gas phase $\mathrm{MoCl}_{6}$ was assumed to have $O_{h}$ symmetry. ${ }^{6 \mathrm{a}}$

$\mathrm{WCl}_{6}$ has a perfect octahedron structure ${ }^{5}$ in the gas phase. The crystal structure of $\mathrm{WCl}_{6}$ confirms its octahedral symmetry, ${ }^{11}$ and in the solid the chlorine atoms have a deformed hexagonal close-packed arrangement. The measured vapor pressure of $\mathrm{WCl}_{6}$ shows a relatively low volatility for this compound. ${ }^{5}$

C. Theoretical Investigations of the Electronic Structure of the Halides of the Transactinides. There are very few publications dealing with calculations of the electronic structure of the transactinide halides. In ref 12 results of the calculations of the energy levels using the Dirac-Slater discrete variational method (DS DVM) are presented for $\mathrm{MoF}_{6}, \mathrm{WF}_{6}$, and E106F . Of the chlorides, calculations of the electronic structure of the group 4 tetrachlorides, $\mathrm{MCl}_{4}(\mathrm{M}=\mathrm{Zr}, \mathrm{Hf}$, and element 104), have been performed using the self-consistent-field $X_{\alpha}$-scattering-wave method (SCF- $\left.X_{\alpha}-S W\right)^{13,14}$ and the DS DVM. ${ }^{15}$

In our earlier works ${ }^{16}$ we have calculated the electronic structure of group 5 halides, $\mathrm{MCl}_{5}$ and $\mathrm{MBr}_{5}(\mathrm{M}=\mathrm{V}, \mathrm{Nb}, \mathrm{Ta}$, and $\mathrm{Ha})$, analyzed the influence of relativistic effects on physicochemical properties, and made some estimates of the volatility of the pentabromides.

Since groups 4 and 6 also belong to the subject of the experimental investigations, a necessity emerged to compare all three groups with respect to the electronic structure characteristics and trends in the physicochemical properties. As was said in the beginning, due to the decrease in the stability of the highest 
TABLE 1: Effective Charges on the Metal Atom $Q_{M}$ and Total Overlap Populations (OP) for $\mathrm{MCl}_{4}$, Where $\mathrm{M}=\mathrm{Zr}$, Hf, and Element 104

\begin{tabular}{lccc}
\hline & & \multicolumn{2}{c}{ DS DVM } \\
\cline { 3 - 4 } molecule & SCF X ${\text { ref } 14^{a}}^{c}$ & ref $15^{b}$ & present work $^{c}$ \\
\hline $\mathrm{Q}_{\mathrm{M}}\left(\mathrm{ZrCl}_{4}\right)$ & 2.36 & 1.03 & 1.18 \\
$\mathrm{Q}_{\mathrm{M}}\left(\mathrm{HfCl}_{4}\right)$ & 2.34 & 0.91 & 1.04 \\
$\mathrm{Q}_{\mathrm{M}}\left(\mathrm{ElO4Cl}_{4}\right)$ & 2.30 & 0.96 & 1.07 \\
$\mathrm{OP}\left(\mathrm{ZrCl}_{4}\right)$ & & 0.63 & 0.48 \\
$\mathrm{OP}\left(\mathrm{HfCl}_{4}\right)$ & & 0.69 & 0.55 \\
$\mathrm{OP}\left(\mathrm{ElO4Cl}_{4}\right)$ & & 0.69 & 0.57
\end{tabular}

${ }^{a}$ Calculations for $R_{\mathrm{Zr}-\mathrm{Cl}}=2.32 \AA, \mathrm{R}_{\mathrm{Hf}-\mathrm{Cl}}=2.33 \AA$, and $\mathrm{R}_{104-\mathrm{Cl}}=2.39$ A. ${ }^{b}$ Calculations for $\mathrm{R}_{\mathrm{Zr}-\mathrm{Cl}}=2.32 \AA, \mathrm{R}_{\mathrm{Hf}-\mathrm{Cl}}=2.33 \AA$, and $\mathrm{R}_{\mathrm{I04-Cl}}=$ $2.50 \AA$. ${ }^{c}$ Calculations for $R_{\mathrm{Zr}-\mathrm{Cl}}=2.32 \AA, \mathrm{R}_{\mathrm{Hf}-\mathrm{Cl}}=2.316 \AA$, and $\mathrm{R}_{104-\mathrm{Cl}}$ $=2.36 \AA$.

chlorides in going from group 4 to group 6, it is very important to estimate the stability of the highest halides of element 105 and especially 106 toward both the thermal decomposition and the process of reduction. Thus, in addition to our earlier calculations of the electronic structure of the group 5 pentachlorides, we have calculated the electronic structure of the group 4 tetrachlorides (to include them in our systematic investigation) and of the group 6 hexachlorides $\mathrm{MCl}_{6}(\mathrm{M}=\mathrm{Mo}, \mathrm{W}$, and element 106$)$.

In the following sections we present results of the calculations of the group 4 and 6 highest chlorides, along with our earlier results for the group 5 pentachlorides, and make comparison between the groups with respect to the electronic structure, related properties, and stabilities of the systems.

Details of the calculations are given in section II. The results of the calculations and their analysis are presented in section III. Section IV is devoted to new estimates of the redox potentials for element 104.

\section{Method and Details of the Calculations}

Calculations have been performed using the DS DVM, a description of which is given elsewhere. ${ }^{16,17}$ Neutral and extended basis sets including valence $\mathrm{np}_{1 / 2}$ and $n p_{3 / 2}$ orbitals were used to examine the influence of these orbitals on chemical bonding. Numerical integration was done using 9000 integration points. Mulliken population analysis ${ }^{13}$ was used to study the charge density distribution data.

For $\mathrm{ZrCl}_{4}$ and $\mathrm{HfCl}_{4}$ experimental bond lengths ${ }^{9 \mathrm{~b}}$ equal to 2.32 and $2.316 \AA$, respectively, have been used as input parameters. For the tetrachloride of element $104\left(\mathrm{RfCl}_{4}\right)$, the $\mathrm{M}-\mathrm{Cl}$ distance was chosen as $2.36 \AA$, taking into account the ionic radius obtained from the multiconfiguration Dirac-Fock (MCDF) calculations ${ }^{19}$ and relativistic bond contraction, which was estimated as $6.5 \%$ (see ref $16 \mathrm{~d}$ ).

For $\mathrm{WCl}_{6}$ an experimental bond length for $\mathrm{W}-\mathrm{Cl}$ of $2.26 \AA$ was used. ${ }^{9 a}$ For $\mathrm{MoCl}_{6}$, a bond length of $2.26 \AA$ has been assumed, in accordance with earlier estimates. ${ }^{9 c}$ (Calculations have also been done for the $\mathrm{Mo}-\mathrm{Cl}$ separation of $2.25 \AA$ estimated on the basis of the difference in the ionic radii between Mo and W.) For E106Cl $\mathrm{Cl}_{6}$ the metal-chlorine separation was assumed to be 2.32 $\AA$ by taking into account a decrease in bond lengths in the row

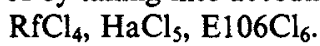

\section{Results of the Calculations and Discussion}

A. Comparison with the $\mathrm{Other}$ Calculations. Comparing results of the calculations (refs 12-15 and our present work) of the electronic structure of $\mathrm{E} 104 \mathrm{Cl}_{4}$, we can say that all of them come to an agreement that the electronic structure of this compound is similar to that of $\mathrm{HfCl}_{4}$, and the bonding is typical of the transition d element compounds. There are some descrepancies in the values of effective charges and overlap populations (Table 1). The results of the calculations ${ }^{15}$ are consistent with our present calculations, though few descrepancies (no increase in the overlap

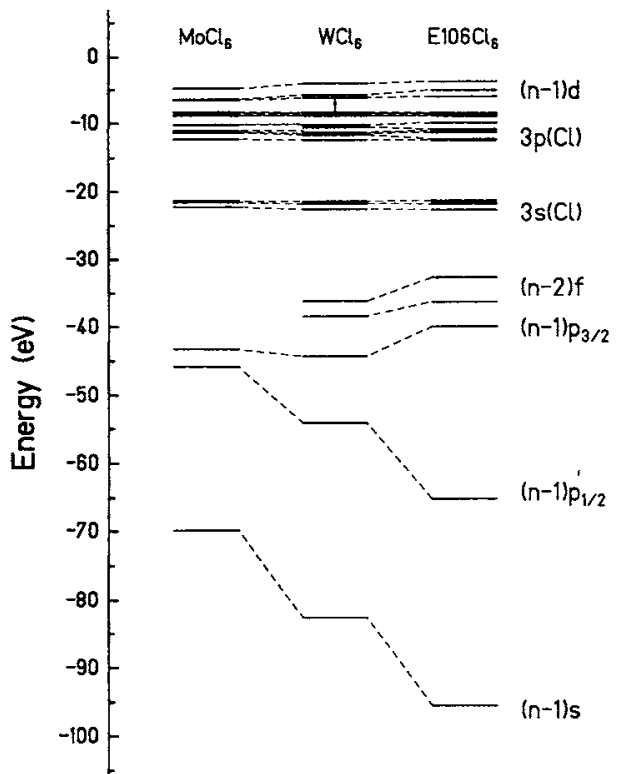

Figure 1. Energy levels for the group 6 hexachlorides $\mathrm{MCl}_{6}(\mathrm{M}=\mathrm{Mo}$, W, and E106).

TABLE 2: Energies of the Highest MOs, Ionization Potentials (IP), Energy Gaps $(\Delta E)$, Energies of the Charge-Transfer Transitions $\left(\Delta E_{\pi-d}\right)$, Crystal-Field Parameters $(\Delta)$, and Spin-Orbit Splittings $\left(\Delta E_{S O}\right)$ of the $t_{2 g}$ Level (in eV) for the Group 6 Hexachlorides

\begin{tabular}{lccc}
\hline & $\mathrm{MoCl}_{6}$ & $\mathrm{WCl}_{6}$ & $\mathrm{E} 106 \mathrm{Cl}_{6}$ \\
\hline $\mathrm{D} 8_{g}$ & -4.81 & -4.07 & -3.76 \\
$\mathrm{D} 7_{g}$ & -6.42 & -5.78 & -5.03 \\
$\mathrm{D} 8_{g}{ }^{g}$ & -6.57 & -6.21 & -5.99 \\
$\mathrm{D} 8_{g}{ }^{b}$ & -8.32 & -8.40 & -8.45 \\
$\mathrm{IP}$ & 11.06 & 11.13 & 11.17 \\
$\Delta \mathrm{E}$ & 1.75 & 2.19 & 2.46 \\
$\Delta \mathrm{E}_{\boldsymbol{x}-\mathrm{d}}$ & 1.92 & 2.37 & 2.65 \\
$\Delta$ & 1.76 & 2.14 & 2.23 \\
$\Delta \mathrm{E}_{\text {So }}\left(\mathrm{t}_{2 \mathrm{~g}}\right)$ & 0.15 & 0.43 & 0.96
\end{tabular}

${ }^{a}$ Lowest unoccupied MO (LUMO), responsible for the electron affinity. ${ }^{b}$ Highest occupied MO (HOMO), responsible for the ionization potential.

population $\mathrm{E} 104-\mathrm{Cl}$ relative to $\mathrm{Hf}-\mathrm{Cl}$ ) are accounted for in the too large $\mathrm{E} 104-\mathrm{Cl}$ interatomic distances chosen in ref 15 . Both results show the same trend in the ionicity within the group: decrease in the values of the effective charges but with the minimum on Hf. According to the calculations, ${ }^{14}$ the tetrachlorides are more ionic and the effectivecharge on E104 is the lowest in the series. Thus, our results in agreement with those of ref 15 show the element 104 tetrachloride to be a rather covalent compound, with the covalency being larger than that of $\mathrm{HfCl}_{4}$.

B. Electronic Structure of the Hexachlorides of $\mathrm{Mo}, \mathrm{W}$, and E106. Energy level structures for $\mathrm{MoCl}_{6}, \mathrm{WCl}_{6}$, and $\mathrm{E} 106 \mathrm{Cl}_{6}$ are shown in Figure 1. Table 2 gives the results of the calculations of the energies of the highest occupied $\mathrm{MO}$ of $3 \mathrm{p}(\mathrm{Cl})$ character and of the vacant MOs of $d$ character, the energy gap between the occupied and the vacant levels, crystal-field and spin-orbit parameters, the energies of the charge-transfer transitions, and the ionization potentials. From these data one can see that, by analogy with group 5 pentahalides, ${ }^{16 a}$ there is an increase in the energy gap between the bonding (occupied) and nonbonding (vacant) levels in going from the Mo to the E106 hexachlorides. There is an increase in the crystal-field and spin-orbit splittings, as well as in the molecular ionization potentials, and a decrease in the electronic affinities in this direction.

In contrast to $\mathrm{HaCl}_{5}$, the electronic structure of the vacant levels of $\mathrm{d}$ character in $\mathrm{E} 106 \mathrm{Cl}_{6}$ is not influenced by a strong relativistic stabilization of the 7s orbital. Due to the $O_{h}$ symmetry, the $7 \mathrm{~s}$ orbital does not contribute to the highest vacant MO of 


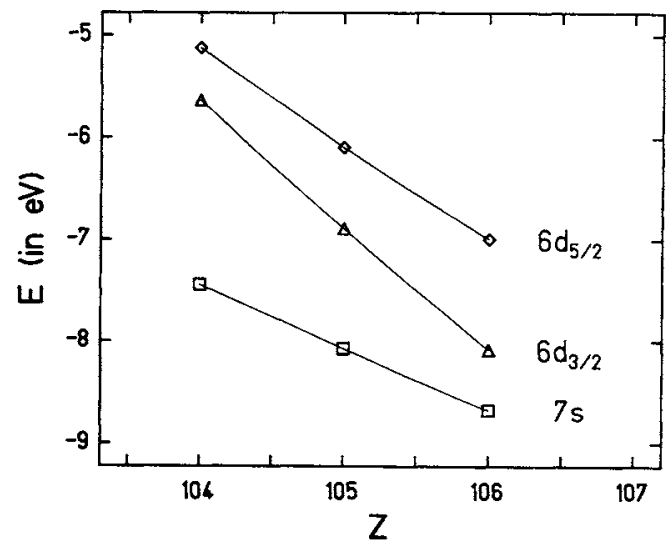

Figure 2. Binding energies of $7 \mathrm{~s}$ and $6 \mathrm{~d}$ orbitals for elements 104,105 , and 106 as a result of the DF calculations. ${ }^{20}$

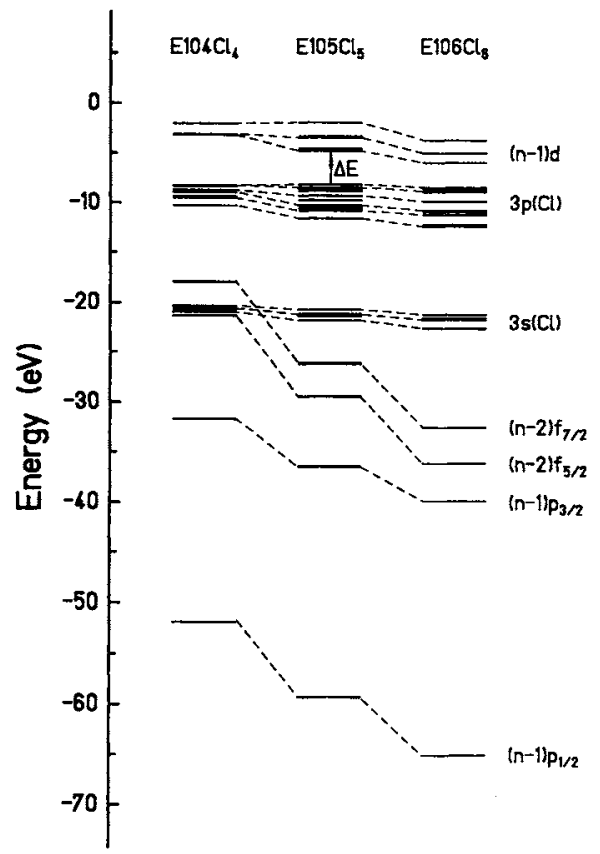

Figure 3. Energy eigenvalues for the highest chlorides of elements 104, 105 , and 106.

d character. Thus, the main composition of the highest unoccupied orbital in $\mathrm{E} 106 \mathrm{Cl}_{6}$ is the following: $9 \%\left(6 \mathrm{~d}_{3 / 2}\right), 50 \%\left(6 \mathrm{~d}_{5 / 2}\right)$, and $36 \%(3 \mathrm{p}(\mathrm{Cl}))$.

The charge density distribution data will be shown in the next section when comparing results for groups 4,5 , and 6 .

C. Comparison of the Electronic Structure Data and Properties for Group 4, 5, and 6 Highest Chlorides. 1. Energy Levels. DiracFock binding energies ${ }^{20}$ of the valence $s$ and $\mathrm{d}$ electrons for $\mathrm{Rf}$, $\mathrm{Ha}$, and E106 are shown in Figure 2. They reflect the following trend: the $s$ electrons become more bound with increasing $Z$ due to relativistic effects; the $6 \mathrm{~d}$ electrons, though destabilized by relativistic effects, are more bound with increasing $Z$ due to the larger shell-structure effect. Spin-orbit splitting of the $6 \mathrm{~d}$ orbitals increases in this direction. As a reflection of this trend, the first atomic ionization potentials increase in going from element 104 to element 106. (For element 104 the first ionized electron is $7 p_{1 / 2 .)}$

The trend in the energies of the atomic levels (Figure 2) is manifested in the structures of molecular levels for $\mathrm{RfCl}_{4}, \mathrm{HaCl}_{5}$, and $\mathrm{E} 106 \mathrm{Cl}_{6}$, which are shown in Figure 3. One can see that there is a lowering of the sets of the $d$ levels with increasing $Z$. The change in the crystal-field splitting of the $d$ orbitals is connected with their different splittings in the fields of $T_{\mathrm{d}}, D_{3 h}$, and $O_{h}$ symmetry. The crystal-field parameter $\Delta$ of $1.17 \mathrm{eV}$ for $\mathrm{RfCl}_{4}$ in $T_{\mathrm{d}}$ symmetry is smaller than the $\Delta$ for $\mathrm{HaCl}_{5}$ of 3.33
TABLE 3: Effective Charges $\left(Q_{M}\right)$, Total Overlap Populations (OP), and Populations for One $\mathrm{M}-\mathrm{Cl}$ Bond for the Highest Chlorides of Groups 4, 5, and 6

\begin{tabular}{lllllll}
\hline & \multicolumn{2}{c}{$\mathrm{MCl}_{4}$} & \multicolumn{2}{c}{$\mathrm{MCl}_{5}$} & \multicolumn{2}{c}{$\mathrm{MCl}_{6}$} \\
\hline$Q_{\mathrm{M}}$ & $\mathrm{Zr}$ & 1.18 & $\mathrm{Nb}$ & $\mathbf{0 . 9 3}$ & $\mathrm{Mo}$ & 0.79 \\
& $\mathrm{Hf}$ & 1.04 & $\mathrm{Ta}$ & $\mathbf{0 . 9 5}$ & $\mathrm{W}$ & 0.74 \\
OP(tot) & $\mathrm{Rf}$ & 1.07 & $\mathrm{Ha}$ & $\mathbf{0 . 8 1}$ & $\mathrm{E} 106$ & 0.59 \\
& $\mathrm{Zr}$ & 1.92 & $\mathrm{Nb}$ & 2.04 & $\mathrm{Mo}$ & 2.18 \\
& $\mathrm{Hf}$ & 2.21 & $\mathrm{Ta}$ & 2.49 & $\mathrm{~W}$ & 2.75 \\
OP(M-Cl) & $\mathrm{Rf}$ & 2.28 & $\mathrm{Ha}$ & 2.60 & $\mathrm{E} 106$ & 2.72 \\
& $\mathrm{Zr}$ & 0.48 & $\mathrm{Nb}$ & $\mathbf{0 . 4 1}$ & $\mathrm{Mo}$ & 0.36 \\
& $\mathrm{Hf}$ & 0.55 & $\mathrm{Ta}$ & $\mathbf{0 . 5 0}$ & $\mathrm{W}$ & 0.46 \\
& $\mathrm{Rf}$ & 0.57 & $\mathrm{Ha}$ & 0.52 & $\mathrm{E} 106$ & 0.45
\end{tabular}

$\mathrm{eV}$ in $D_{3 h}$ and the $\Delta$ of $2.22 \mathrm{eV}$ for $\mathrm{E}_{106 \mathrm{Cl}_{6}}$ in $O_{h}$ symmetry. The value of the energy gap diminishes in going from element 104 to element 106 and is equal to $4.98,3.25$, and $2.46 \mathrm{eV}$ for $\mathrm{RfCl}_{4}$, $\mathrm{HaCl}_{5}$, and $\mathrm{E} 106 \mathrm{Cl}_{6}$, respectively. The molecular ionization potentials are $10.96,10.75$, and $11.17 \mathrm{eV}$, respectively.

2. Charge Density Distribution. In Table 3 effective charges $\left(Q_{\mathrm{M}}\right)$ and overlap population data (OP) for $\mathrm{MCl}_{4}(\mathrm{M}=\mathrm{Zr}$, Hf, and $R f), M C_{5}(M=N b, T a$, and $\mathrm{Ha})$, and $\mathrm{MCl}_{6}(\mathrm{M}=\mathrm{Mo}, \mathrm{W}$, and E106) are given as a result of our present DS DVM calculations. These data show that trends in the charge density distribution within the groups under investigation are basically similar: there is an increase in covalency (OP data) and a decrease in ionicity $\left(Q_{M}\right)$; but there are also differences. The values of $Q_{M}$ decrease in group 6 in going from Mo to E106. In group 5 they are nearly equal for $\mathrm{Nb}$ and $\mathrm{Ta}$, and in group 4 there is no decrease in $Q_{M}$ in going from $\mathrm{Hf}$ to $\mathrm{Rf}$. The covalency (OP data), on the contrary, increases within groups 4 and 5 , but for group 6 the total OP for $\mathrm{E}^{106 \mathrm{Cl}_{6}}$ is lower than that for $\mathrm{WCl}_{6}$.

The covalent strength of one $\mathrm{M}-\mathrm{Cl}$ bond for the $\mathrm{MCl}_{n}$ molecules is shown in the lower part of Table 3 as a partial $\mathrm{M}-\mathrm{Cl}$ overlap population. The low value of the $\mathrm{OP}(\mathrm{Mo}-\mathrm{Cl})$ in $\mathrm{MoCl}_{6}$ explains the instability of this compound toward thermal decomposition. The higher values of the $\mathrm{OP}(\mathrm{M}-\mathrm{Cl})$ for the $5 \mathrm{~d}$ element chlorides compared to the $4 \mathrm{~d}$ chlorides and their not much different values of $Q_{\mathrm{M}}$ are the reason for their higher stability.

The different trends in the values of the effective charges and overlap populations result in different trends in bonding $\mathrm{M}-\mathrm{Cl}$ for groups 4,5 , and 6 . Thus, though the covalency increases within the groups with increasing $Z$, this increase diminishes in going from group 4 to group 6 . In $\mathrm{RfCl}_{4}$, both covalent and ionic contributions to bonding make the metal-ligand bond obviously stronger than that of $\mathrm{HfCl}_{4}$. In $\mathrm{HaCl}_{5}$, the covalent part of the bonding energy is larger than that in $\mathrm{TaCl}_{5}$, but a very low ionic contribution might make the bonding weaker than that in $\mathrm{TaCl}_{5}$. In group $6, \mathrm{E} 106 \mathrm{Cl}_{6}$ has a lower covalent bonding energy than that in $\mathrm{WCl}_{6}$ and a very low ionic contribution. That means that the $\mathrm{M}-\mathrm{Cl}$ bond strength in $\mathrm{E}^{106 \mathrm{Cl}_{6}}$ should be weaker than that in $\mathrm{WCl}_{6}$.

3. Thermochemical Stability. In ref 16a an estimate of the bond strength for $\mathrm{HaCl}_{5}$ has been made using a correlation between the OP data for $\mathrm{NbCl}_{5}, \mathrm{TaCl}_{5}$, and $\mathrm{HaCl}_{5}$ and the covalent binding energies. The latter values were obtained by subtracting the ionic bonding energy (calculated using the values of the effective charges $Q_{\mathrm{M}}$ for the $\mathrm{MCl}_{5}$ molecules) from the dissociation energies $\Delta H_{\text {diss }}$ obtained from the Born-Haber cycle for the formation of $\mathrm{MCl}_{5}(\mathrm{~g})$.

We can use the same approach here to estimate the dissociation energy of $\mathrm{RfCl}_{4}$ and $\mathrm{E} 106 \mathrm{Cl}_{6}$ using the Born-Haber cycle for the formation of the gaseous molecules $\mathrm{MCl}_{4}$ and $\mathrm{MCl}_{6}$. The dissociation energy is then

$$
\begin{aligned}
& \Delta H_{\text {diss }}\left(\mathrm{MX}_{n}\right)= \\
& \quad \Delta H_{\text {subl }}(\mathrm{M})+n \Delta H_{\text {form }}(\mathrm{Cl})-\Delta H_{\text {form }}\left(\mathrm{MX}_{n}, \mathrm{~g}\right)
\end{aligned}
$$

where the enthalpies are taken at $298.15 \mathrm{~K}$. 
TABLE 4: Average Thermochemical M-Cl Bond Energies for the Highest Chlorides of Groups 4, 5, and 6a,b

\begin{tabular}{cccccc}
\hline $\mathrm{MCl}_{4}$ & $\begin{array}{c}E, \\
\mathrm{kcal} / \mathrm{mol}\end{array}$ & $\mathrm{MCl}_{5}$ & $\begin{array}{c}E, \\
\mathrm{kcal} / \mathrm{mol}\end{array}$ & \multicolumn{1}{c}{$\mathrm{MCl}_{6}$} & $\begin{array}{c}E, \\
\mathrm{kcal} / \mathrm{mol}\end{array}$ \\
\hline $\mathrm{ZrCl}_{4}$ & 117.3 & $\mathrm{NbCl}_{5}$ & 97.1 & $\mathrm{MoCl}_{6}$ & 73.8 \\
$\mathrm{HfCl}_{4}$ & 118.4 & $\mathrm{TaCl}_{5}$ & 102.6 & $\mathrm{WCl}_{6}$ & 83.2 \\
$\mathrm{RfCl}_{4}$ & $122.9^{c}$ & $\mathrm{HaCl}_{5}$ & $95.7^{\mathrm{c}}$ & $\mathrm{E}^{106 C_{6}}$ & $77.3^{\mathrm{c}}$
\end{tabular}

a Since we are interested in the decomposition into atoms, we did not calculate valence bond energies. In addition, the excitation energies from the ground states of the metals to the valence states realized in the molecules are not known for elements 104,105 , and $106 .{ }^{b}$ Calculated from experimental thermochemical $\Delta \mathrm{H}_{\text {diss. }}$. For comparison $E(\mathrm{Zr}-\mathrm{Cl})=$ $115.6 \mathrm{kcal} \mathrm{mol} ; E(\mathrm{~W}-\mathrm{Cl})=73.7 \mathrm{kcal} / \mathrm{mol}^{21}$ The latter value seems to be too low. ${ }^{c}$ Calculated values using $\Delta \mathbf{H}_{\text {diss }}$ estimated in this work.

Using $\Delta H_{\text {form }}(g)$ for $\mathrm{ZrCl}_{4}, \mathrm{HfCl}_{4}, \mathrm{MoCl}_{6}, \mathrm{WCl}_{6}$ (refs 6, 7), $\Delta H_{\text {subl }}(\mathrm{M})($ refs 5,9$)$, and $1 / 2 \Delta H_{\text {diss }}\left(\mathrm{Cl}_{2}\right)$ equal to $28.989 \mathrm{kcal} /$ mol, one can calculate $\Delta H_{\text {diss }}$ for these molecules. The obtained values of $\Delta H_{\text {diss }}$ are 469.4 and $473.8 \mathrm{kcal} / \mathrm{mol}$ for $\mathrm{ZrCl}_{4}$ and $\mathrm{HfCl}_{4}$, and 442.9 and $499.2 \mathrm{kcal} / \mathrm{mol}$ for $\mathrm{MoCl}_{6}$ and $\mathrm{WCl}_{6}$, respectively. The ionic parts of the binding energy, $E_{\mathrm{i}}$, calculated from the $Q_{\mathrm{M}}$ values (Table 2) are 8.5, 6.64, and $6.94 \mathrm{eV}$ for $\mathrm{ZrCl}_{4}, \mathrm{HfCl}_{4}$, and $\mathrm{RfCl}_{4}$, respectively. For $\mathrm{MoCl}_{6}, \mathrm{WCl}_{6}$, and $\mathrm{E} 106 \mathrm{Cl}_{6}$ these values are $3.97,3.47$, and $2.15 \mathrm{eV}$, respectively. The covalent part of the binding energy was obtained using the equation $E_{\mathrm{c}}=\Delta H_{\text {diss }}-E_{\mathrm{j}}$. A linear correlation between the covalent binding energy, $E_{\mathrm{c}}$, and total OP for $\mathrm{MCl}_{4}(\mathrm{M}=\mathrm{Zr}, \mathrm{Hf}$, and $\mathrm{Rf}$ ) and a similar correlation between $E_{\mathrm{c}}$ and $\mathrm{OP}$ for $\mathrm{MCl}_{6}$ (M= Mo, W, and E106) give the following values of $E_{\mathrm{c}}$ for $\mathrm{RfCl}_{4}$

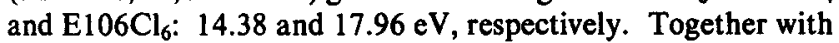
$E_{\text {i }}$, these values give heats of dissociation for $\mathrm{RfCl}_{4}$ and $\mathrm{E} 106 \mathrm{Cl}_{6}$ of $21.32 \mathrm{eV}(491.6 \mathrm{kcal} / \mathrm{mol})$ and $20.11 \mathrm{eV}(463.7 \mathrm{kcal} / \mathrm{mol})$, respectively. Division of the $\Delta H_{\text {diss }}$ by the number of bonds gives the metal-chlorine thermochemical bond energy. These values for the chlorides under consideration are given in Table 4.

Thus, the groups show different trends in the stability of the gaseous chlorides toward thermal decomposition. $\mathrm{RfCl}_{4}$ should be more stable than $\mathrm{HfCl}_{4}$ and $\mathrm{ZrCl}_{4}$, but the stability of $\mathrm{HaCl}_{5}$ is on the order of the stability of $\mathrm{NbCl}_{5}$. As was mentioned in the introduction, $\mathrm{MoCl}_{6}$ is known to be unstable with respect to the loss of a chlorine atom: $\mathrm{MoCl}_{6} \rightarrow \mathrm{MoCl}_{5}+1 / 2 \mathrm{Cl}_{2}$. Our calculated relatively low average bond energy (Table 3 ) confirms this fact. $\mathrm{WCl}_{6}$ is stable only up to its boiling point of $346^{\circ} \mathrm{C}$; at higher temperatures it undergoes decomposition: $\mathrm{WCl}_{6} \rightarrow$ $\mathrm{WCl}_{5}+{ }_{1 / 2} \mathrm{Cl}_{2}$. The metal chlorine bond energy obtained for E106 $\mathrm{Cl}_{6}$ is indicative of a stability of this compound lower than that of $\mathrm{WCl}_{6}$, losing chlorine at temperatures below $346^{\circ} \mathrm{C}$.

The knowledge of the enthalpy for the reaction of the decomposition with the loss of one chlorine,

$$
\mathrm{MCl}_{n} \rightarrow \mathrm{MCl}_{n-1}+{ }^{1} / 2 \mathrm{Cl}_{2}
$$

is, therefore, of importance. The $\Delta H_{\text {diss }}^{\prime}$ for reaction 2 is known ${ }^{5}$ to be 28.3 and $33.6 \mathrm{kcal} / \mathrm{mol}$ for $\mathrm{NbCl}_{5}$ and $\mathrm{TaCl}_{5}$, respectively, and $24.2 \mathrm{kcal} / \mathrm{mol}$ for $\mathrm{WCl}_{6}$. In ref $6 \mathrm{~d} \Delta H_{\text {diss }}^{\prime}$ is given as 4 $\mathrm{kcal} / \mathrm{mol}$ at $445 \mathrm{~K}$. Assuming that $\Delta H_{\text {diss }}^{\prime}$ is proportional to the average bond energy, one can estimate $\Delta H_{\text {diss }}^{\prime}$ for $\mathrm{HaCl}_{5}$ and E106 $\mathrm{Cl}_{6}$ from the $\Delta H_{\text {diss }}^{\prime}$ for the lighter homologues. Thus, the enthalpies of dissociation for reaction 1 will be

$$
\begin{aligned}
& \mathrm{HaCl}_{5} \rightarrow \mathrm{HaCl}_{4}+{ }^{1} /{ }_{2} \mathrm{Cl}_{2} \quad \Delta H_{\text {diss }}^{\prime}=27.8 \mathrm{kcal} / \mathrm{mol}
\end{aligned}
$$

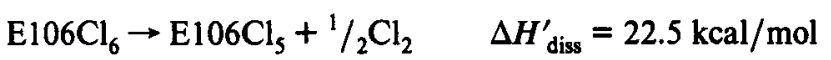

4. Enthalpies of Formation. Using the estimates of $\Delta H_{\text {diss }}$ (for the total decomposition into atoms), one can calculate $\Delta H_{\text {form }}(\mathrm{g})$ for $\mathrm{RfCl}_{4}, \mathrm{HaCl}_{5}$, and $\mathrm{E} 106 \mathrm{Cl}_{6}$ using the Born-Haber cycle (eq 1$)$. In refs 14 and 22 estimates of $\Delta H_{\text {subl }}(\mathrm{Rf})$ are given

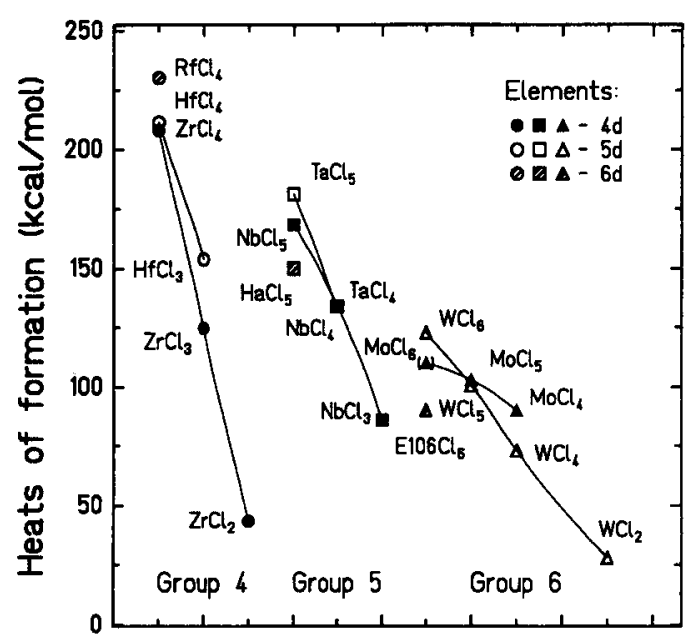

\section{Elements}

Figure 4. Formation enthalpies of gaseous chlorides of groups 4, 5, and 6. Experimental values for the 4d and $5 d$ elements are taken from refs 7 and 8 . An estimated $\Delta H_{\text {form }}\left(\mathrm{MoCl}_{6}, \mathrm{~g}\right)$ of $-110.28 \mathrm{kcal} / \mathrm{mol}$ is from ref 6. The values for $\mathrm{E} 104 \mathrm{Cl}_{4}, \mathrm{HaCl}_{5}$, and $\mathrm{E} 106 \mathrm{Cl}_{6}$ are estimated ones (this work).

as 145.8 and $151.4 \pm 9 \mathrm{kcal} / \mathrm{mol}$, respectively. The sublimation enthalpies of $\mathrm{Ha}$ and E106 were estimated in ref 22 to be 183.5 \pm 7 and $200 \pm 6 \mathrm{kcal} / \mathrm{mol}$, respectively. Using $\Delta H_{\text {subl }}$ for Rf, $\mathrm{Ha}$, and $\mathrm{E} 106$, we have obtained $\Delta H_{\text {form }}(\mathrm{g})$ for $\mathrm{RfCl}_{4}, \mathrm{HaCl}_{5}$, and $\mathrm{E} 106 \mathrm{Cl}_{6}$ of $-229.9,-150.05 \pm 7$, and $-90.3 \pm 6 \mathrm{kcal} / \mathrm{mol}$, respectively. These values along with the other known values for the gaseous chlorides of groups 4, 5, and 6 are shown in Figure 4.

Thus, the enthalpy of formation of $\mathrm{E} 106 \mathrm{Cl}_{6}(\mathrm{~g})$ indicates a lower stability of this chloride in the gas phase than that of $\mathrm{MoCl}_{6}$.

Our approach used in the estimations of the formation enthalpies is based on the approximate calculations of the dissociation energies via the described above correlation between the OP and the covalent part of the binding energy. Of course, the precise calculations of the dissociation energies of the $\mathrm{MCl}_{n}$ molecules are needed, which encounter presently some methodical difficulties.

Another approach used in the estimation of the formation enthalpies (ref 23) is based on the assumption that, in general, for elements of one group of the periodic table linear correlations exist between the formation enthalpies of gaseous and solid compounds of analogous species and the sublimation enthalpies of the corresponding gaseous elements. Figure 4 shows that this is not generally the case. In addition, this model assumes a steady increase in the dissociation energies of the compounds in going down the column of the transition elements. But if one accepts that for the highest halides this statement is valid and assumes that the dissociation energies increase in going from the $4 \mathrm{~d}$ to the $6 \mathrm{~d}$ elements, one can estimate the upper limit (in absolute values) for the formation enthalpies of the highest chlorides of the transactinides using this model.

Thus, for the solid pentachlorides of group 5, as an example, the following equation holds using data from ref 7 :

$$
\Delta H_{\text {form }}\left(\mathrm{MCl}_{5}, \mathrm{~s}\right)=0.99 \Delta H_{\text {form }}(\mathrm{M})+20.33(\mathrm{kcal} / \mathrm{mol})
$$

and for the gaseous chlorides

$\Delta H_{\text {form }}\left(\mathrm{MCl}_{5}, \mathrm{~g}\right)=0.89 \Delta H_{\text {form }}(\mathrm{M})+15.98(\mathrm{kcal} / \mathrm{mol})$

Using our calculated $22 \Delta H_{\text {form }}(\mathrm{Ha})$ of $183.7 \pm 7 \mathrm{kcal} / \mathrm{mol}$, we obtain $\Delta H_{\text {form }}\left(\mathrm{HaCl}_{5}, \mathrm{~s}\right)$ of $202.0 \pm 7 \mathrm{kcal} / \mathrm{mol}$ and $\Delta H_{\text {form }}\left(\mathrm{HaCl}_{5}\right.$, g) of $178.4 \pm 7 \mathrm{kcal} / \mathrm{mol}$. Thus, using this model, the formation enthalpies of $\mathrm{HaCl}_{5}$ are between those values for $\mathrm{NbCl}_{5}$ and $\mathrm{TaCl}_{5}$; 


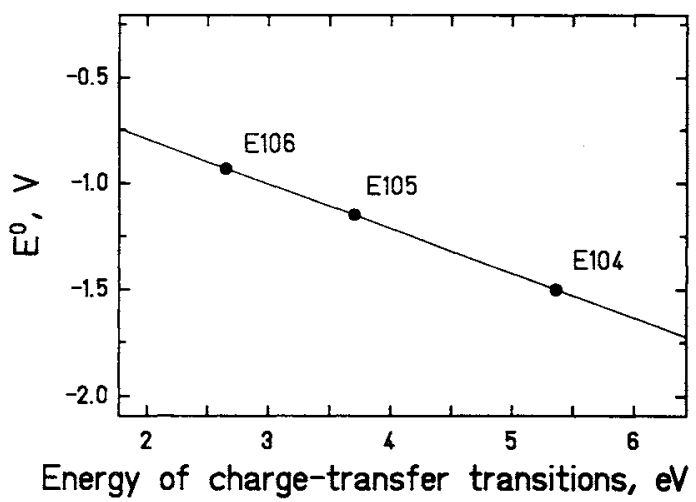

Figure 5. Correlation between redox potentials ${ }^{28}$ corresponding to the electronic transitions from the highest to the next lower oxidation states and related energies of the charge-transfer transitions in $\mathbf{M C l}_{n}$ for elements 104,105 , and 106.

TABLE 5: Standard Reduction Potentials $E^{\circ}\left(M^{z+x} / M^{x+}\right)$ in (Volts) for Heavy Elements

\begin{tabular}{lcccc}
\hline element & $\begin{array}{c}E^{\circ}\left(\mathrm{M}^{3+} /\right. \\
\left.\mathrm{M}^{2+}\right)^{a}\end{array}$ & $\begin{array}{c}E^{\circ}\left(\mathrm{M}^{4+} /\right. \\
\left.\mathbf{M}^{3+}\right)^{a}\end{array}$ & $\begin{array}{c}E^{\circ}\left(\mathbf{M}^{5+} /\right. \\
\left.\mathbf{M}^{4+}\right)\end{array}$ & $\begin{array}{c}E^{\circ}\left(\mathbf{M}^{6+} /\right. \\
\left.\mathbf{M}^{5+}\right)\end{array}$ \\
\hline E102(No) & 1.3 & 6.6 & & \\
E103(Lr) & -2.6 & 8.1 & & \\
E104(Rf) & -1.7 & -1.5 & & \\
E105(Ha) & $-1.20^{b}$ & $-1.38^{b}$ & $-1.0^{b}$ & \\
E106 & & & & $-0.93^{c}$
\end{tabular}

${ }^{a}$ Reference $26 .{ }^{b}$ Reference $24 .{ }^{c}$ This work.

but taking into account the fact that the dissociation energies of the pentachlorides decrease in going from the tantalum to the hafnium chloride, the formation enthalpies (absolute values) will be even smaller. A similar case could be considered for the group 6 chlorides.

Thus, one can see that the trends in some properties, like, for example, in the dissociation energies, formation enthalpies do not continue from the $5 \mathrm{~d}$ to the $6 \mathrm{~d}$ halides in going to the right of the periodic table.

5. Stability of the Maximum Oxidation State. Besides the decrease in the stability toward dissociation, the stability of the maximum oxidation state decreases in going from group 4 to group 6. Earlier correlations ${ }^{24}$ of atomic ionization potentials corresponding to transitions from the highest to the next lower oxidation state with the related redox potentials have shown the following trend in the stability of the maximum oxidation state: $\mathrm{Lr}(+3)>\mathrm{Rf}(+4)>\mathrm{Ha}(+5)$. Results of the present calculations confirm that this trend continues to element 106. In Figure 5 the correlation between energies of the charge-transfer transitions in the $\mathrm{MCl}_{n}$ molecules with the redox potentials corresponding to the transitions from the maximum to the next lower oxidation state is shown, giving the value of $E^{\circ}\left(\mathrm{E} 106^{6+} / \mathrm{E} 106^{5+}\right)$ equal to $-0.93 \mathrm{~V}$. The obtained values of the potentials (Table 5) are indicative of a decrease in the stability of the maximum oxidation state: $\mathrm{Rf}(+4)>\mathrm{Ha}(+5)>\mathrm{E} 106(+6)$.

D. Volatility of the Highest Chlorides. Volatility of the highest fluorides is known to increase in going from group 4 to group 6. In Figure 6 the equilibrium vapor pressure $P_{\mathrm{mm}}$ is shown as a function of temperature for group 4, 5, and 6 highest chlorides. ${ }^{5}$ As was mentioned earlier, $P_{\mathrm{mm}}$ of $\mathrm{WCl}_{6}$ shows a relatively low volatility, which is not accounted for by the solid-state structure of this compound consisting of discrete octahedra. (The $\Delta H_{\text {subl }}$ of $21.2 \mathrm{kcal} / \mathrm{mol}$, calculated as a difference between the formation enthalpies of the solid and gaseous $\mathrm{WCl}_{6}$ compounds ${ }^{7}$ is on the order of those values for $\mathrm{NbCl}_{5}$ and $\mathrm{TaCl}_{5}$ of 21.27 and 20.41 $\mathrm{kcal} / \mathrm{mol}$, respectively. ${ }^{25}$ )

The vapor pressure of $\mathrm{MoCl}_{6}$ as a function of temperature has not been measured due to the decomposition of this compound. In ref $6 \mathrm{~d} \mathrm{MoCl}_{6}$ was shown to be less volatile than $\mathrm{MoCl}_{5}$ and

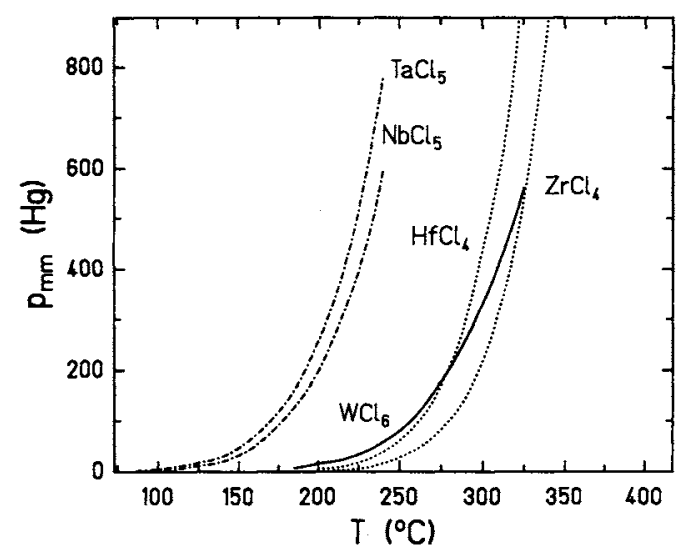

Figure 6. Volatility as a temperature dependence of $P_{\mathrm{mm}}$ for the group 4,5 , and 6 highest chlorides. 5

the vapor pressure, $P_{\mathrm{mm}}(\mathrm{Hg})$, was measured for the reaction $\mathrm{MoCl}_{6}$ $\rightarrow \mathrm{MoCl}_{5}+1 / 2 \mathrm{Cl}_{2}$, with $P_{\mathrm{mm}}$ for $\mathrm{MoCl}_{6}$ being 2 at $170^{\circ} \mathrm{C}$ and 40 at $266^{\circ} \mathrm{C}$.

To show that the more covalent compounds are more volatile, one should look at the values of the total overlap populations (or, in other words, covalency) for the molecules under consideration (Table 2). These values increase in going from group 4 to group 6. This increase in covalency explains partially the increase in the volatility of these species in going from group 4 to group 5 . The higher covalency of the $5 \mathrm{~d}$ compared to the $4 \mathrm{~d}$ halides is also consistent with their higher volatility. Since $\mathrm{WCl}_{6}$ has the highest covalency of any chloride in the entire series of chlorides under study, it should, in principle, have the highest volatility. Thus, the low-pressure $P_{\mathrm{mm}}$ of $\mathrm{WCl}_{6}$ can not be explained either by its solid-state structure or by it having the highest covalency of any of this series of chlorides.

\section{Stability of the Maximum Oxidation State in Group 4}

Estimates of different redox potentials for element 104 have been made in refs 26 and 27 . In ref 26 very approximate values of ionization potentials were used for the estimation of $E^{\circ}$ (IV$0)$. In ref 27 estimates were based on the MCDF ionization potentials, but both papers used a very crude estimate of the $\Delta H_{\text {sub }}$ of the 104 metal. The values (absolute) of the $E^{\circ}(\mathrm{IV}-0)$ from ref 27 seem to be too high. The main conclusion drawn in both papers is that E104(+4) is more stable than E104(+3), and the latter is more stable than E104(+2). The stability of the +1 oxidation state was not analyzed.

The lowest values of the IP(0)-(+1) (ref 27) in group 4 for element 104 are a good indication of the enhanced stability of the +1 oxidation state of this element in comparison with its lighter analogs, $\mathrm{Zr}$ and $\mathrm{Hf}$, for which the oxidation state +1 is, however, not known.

Figures 7 and 8 show our estimates of the reduction potentials $E^{\circ}(I V-0)$ based on the correlation between the known values of $E^{\circ}(\mathrm{IV}-0)$ for $\mathrm{Zr}$ and $\mathrm{Hf}$ and ionization potentials $(0)-(+4)$ from ref 14 using the MCDF method. The values for element 104 show that the earlier estimates (absolute values) of the redox potentials of $-0.8 \mathrm{~V}$ (ref 26) and -1.2 and $-0.9 \mathrm{~V}$ (ref 27) are too low. We find $E^{\circ}\left(\mathrm{MO}_{2} / \mathrm{M}\right)$ equal to $-1.95 \mathrm{~V}$ and $E^{\circ}\left(\mathrm{M}^{4+} /\right.$ $\mathrm{M})$ equal to $-1.85 \mathrm{~V}$.

\section{Conclusion}

Present DS DVM calculations of the group 4, 5, and 6 highest chlorides have shown that the electronic structure parameters and bonding do not change in the same way within each group. Though there is an increase in the covalency within the groups, this increase diminishes in going from group 4 to group 6 . The highest halides of the transactinides show a decrease in the stability with respect to the $\mathrm{M}-\mathrm{Cl}$ bond dissociation with increasing $\mathrm{Z}$. 


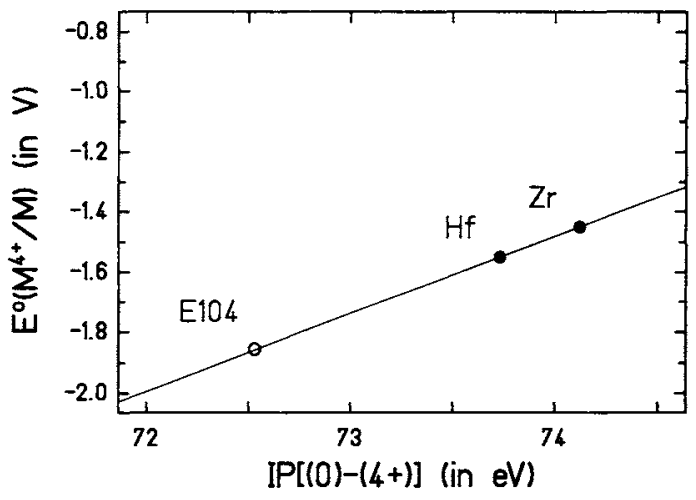

Figure 7. Correlation between calculated ${ }^{19}$ IPs $(0)-(4+)$ and redox potentials $E^{\circ}\left(\mathrm{M}^{4+} / \mathrm{M}^{0}\right)^{28}$ for group 4 elements. The open circle for element 104 is an estimated value of $\mathrm{E}^{\circ}\left(\mathrm{M}^{4+}\right) /\left(\mathrm{M}^{0}\right)$ equal to $-1.85 \mathrm{~V}$.

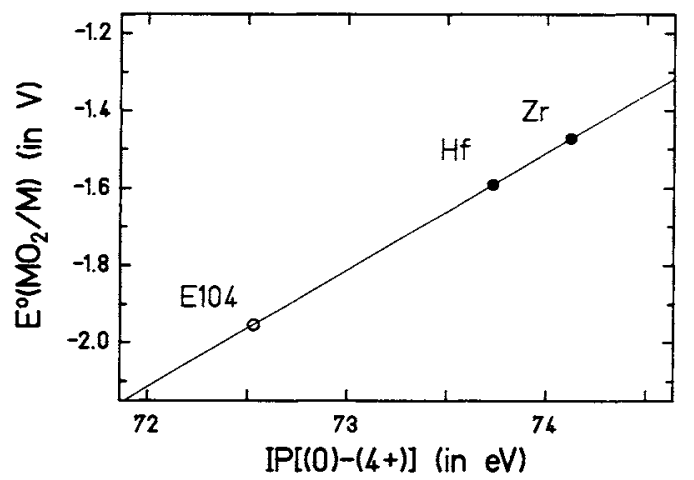

Figure 8. Correlation between calculated ${ }^{19}$ IPs $(0)-(4+)$ and redox potentials $E^{\circ}\left(\mathrm{MO}_{2} / \mathrm{M}\right)^{28}$ for group 4 elements. The open circle for element 104 is an estimated value of $E^{\circ}\left(\mathrm{MO}_{2} / \mathrm{M}\right)$ equal to $-1.95 \mathrm{~V}$.

This means that in group 4 the tetrachloride of element 104 is more stable toward thermal decomposition than the tetrachlorides of $\mathrm{Zr}$ and $\mathrm{Hf}$, while in group 6 the hexachloride of element 106 should be less stable than $\mathrm{WCl}_{6}$, which decomposes at its boiling point. This will induce difficulties in handling the highest chloride of element 106 in the gas-phase chromatography experiments conducted at high temperatures. In addition, the estimated value of the enthalpy of formation of the gaseous $\mathrm{E}^{106 \mathrm{Cl}_{6}}$ is very low, even lower than that of the very unstable $\mathrm{MoCl}_{6}$.

Besides, even though the stability of the maximum oxidation state increases within the groups, it decreases for the elements of the same row in going from group 4 to group 6 . The obtained values of the standard reduction potentials corresponding to the transitions from the highest to the next reduced state show the following sequence in the stability of the maximum oxidation state for the heavy elements: $\operatorname{Lr}(+3)>\mathrm{Rf}(+4)>\mathrm{Ha}(+5)>$ E106(+6).

Thus, in going to the right of the periodic table the trends in some properties within the groups (dissociation energies, formation enthalpies, stabilities of oxidation states after group 6) start to be reversed in going from the $5 \mathrm{~d}$ to the $6 \mathrm{~d}$ elements.

Concerning the gas-phase chromatography experiments, better species for studying volatility of element 106 along with Mo and W would probably be the oxyhalides of these elements, which are known to be less reactive and thermally more stable than the pure chlorides. Although the oxychlorides of Mo and $\mathrm{W}$ are more stable, nevertheless they can exhibit different stabilities. Thus, for example, $\mathrm{WOCl}_{4}$ is relatively stable, but $\mathrm{MoOCl}_{4}$ is thermally unstable, losing chlorine with increasing temperature: $\mathrm{MoOCl}_{4}$ $\rightarrow \mathrm{MoOCl}_{3}$. Among dioxide dichlorides, $\mathrm{MoO}_{2} \mathrm{Cl}_{2}$ is more stable than $\mathrm{WO}_{2} \mathrm{Cl}_{2}{ }^{5}$ Thus, to predict the behavior of the oxyhalide compounds of element 106 in future gas-phase chromatography experiments, investigations of the stability of these compounds based on the calculations of their electronic structure are needed. This will be a subject of our further theoretical investigations.

Acknowledgment. The authors (V.P.) thank the Gesellschaft für Schwerionenforschung (GSI), Darmstadt, for financial support. They also appreciate discussions of the paper with Prof G. V. Ionova.

\section{References and Notes}

(1) (a) Zvara, I.; Belov, V. V.; Chelnokov, L. P.; Domanov, V. P. Hussonnois, M.; Korotkin, Yu. S.; Schchegolev, V. A.; and Shalaevski, M. R. Inorg. Chem. Lett. 1971, 7, 1109. (b) Kadkhodayan, B. On-Line Gas Chromatographic Studies of Rutherfordium (Element 104), Hahnium (Element 105), and Homologs, Doctoral Dissertation; Lawrence Berkeley Laboratory, Report LBL-33961, UC-413, May 1993.

(2) Gäggeler, H. W. Proc. of Int. Conf. "Actinides-93", Santa Fe, September 19-24, 1993; J. Alloys Compd, to be published.

(3) Gäggeler, H. W.; Jost, D. T.; Kovacs, J.; Scherer, U. W.; Weber, A ; Vermeulen, D.; Kratz, J. V.; Gober, M. K.; Zimmermann, H. P.; Schädel, M.; Brüchle, W.; Zvara, I.; Türler, A.; Gregorich, K. E.; Henderson, R. A.; Czerwinski, K. R.; Kadkhodayan, B.; Lee, D. M.; Nurmia, M.; Hoffman, D. C. Radiochim Acta 1992, 57,93.

(4) (a) Second Workshop Chemie Schwerster Elemente, Solothurn, 25 27 May 1993. (b) Gäggeler, H. W.; Jost, D. T.; Kovacs, A.; Schädel, M.; Becker, U.; Kratz, J. V.; Eichler, B.; Hübener, S. GSI Scientific Report 1992 GSI 92-1, ISSN 0174-0814, March 1992; p 321.

(5) Canterfold, J. H.; Colton, R. Halides of the Second and Third Row Transition Metals; Wiley: London, 1968.

(6) (a) Brewer, L. Atomic Energy Rev. 1980, N7, 5. (b) Novikov, G. T.; Galitskij, N. V. Russ. J. Inorg. Chem. 1965, 10, 313. (c) Mercer, M. Chem. Commun. 1967, 2, 119. (d) Novikov, G. Thermodynamic investigation of tungsten chlorides. Dissertation, Leningrad, 1953.

(7) (a) Wagman, D. D.; Evans, W. H.; Parker, V. B.; Schumm, R. H.; Halow, I.; Bailey, S. M.; Churney, K. L.; Nuttall, R. L. J. Phys. Chem. Ref. Data 1982, 11, Suppl. 2. (b) Molecular constants of inorganic compounds; Krasnov, K. S., Ed.; Khimija: Leningrad, 1989; in Russian.

(8) Chase, M. V.; Davies, C. A.; Downey, J. R., Jr.; Frurip, D. J.; McDonald, R. A.; Syverud, A. N. J. Phys. Chem. Ref. Data 1985, 14, Suppl. 1.

(9) (a) Brown, D. In Comprehensive Inorganic Chemistry; Bailar, J. C., Ed.; Pergamon Press: Oxford, 1973; Vol. 3, pp 553-622. (b) Girichev, G. V.; Petrov, V. M.; Giricheva, N. I.; Utkin, A. N.; Petrova, V. N. Zh. Strukt. Khim. 1981, 22, 65. (c) Evans, J. C.; Lo, G. J. S. J. Mol. Spectrosc. 1968, $26,147$.

(10) Ischenko, A. A.; Strand, T. G.; Demidov, A. V.; Spiridonov, V. P. J. Mol. Struct. 1978, 43, 227.

(11) Fergusson, G. E. Halogen Chem. 1967, 3, 276. 218.

(12) Rosen, A.; Fricke, B.; Morovic, T.; Ellis, D. E. J. Phys. C4 1979, 40,

(13) Pershina, V.: Ionova, G. V.; Suraeva, N. I. Croat. Chim. Acta 1989 62,763

(14) Zhuikov, B. L.; Glebov, V. A.; Nefedov, V.S.; Zvara, I.J. Radioanal. Nucl. Chem. 1990, 143, 103.

(15) Ryzhkov, M. V.; Gubanov, V. A.; Zvara, I. Radiochim. Acta 1992. 57,11 .

(16) (a) Pershina, V.; Sepp, W.-D.; Fricke, B.; Rosen, A. J. Chem. Phys. 1992, 96, 8367. (b) Pershina, V.; Sepp, W.-D.; Fricke, B.; Kolb, D.; Schädel, M.; Ionova, G. V.Ibid. 1992, 97, 1116 . (c) Pershina, V.; Sepp, W.-D.; Bastug, T.; Fricke, B.; Ionova, G. V. Ibid. 1992, 97, 1123. (d) Pershina, V.; Fricke B. Ibid. 1993, 99, 1 .

(17) (a) Rosen, A.; Ellis, D. E. J. Chem. Phys. 1975, 62, 3039. (b) Rosen, A. Int. J. Quantum Chem. 1978, 13, 509 .

(18) Mulliken, R. S. J. Chem. Phys. 1955, 23, 1833.

(19) Johnson, E.; Fricke, B.; Keller, O. L., Jr.; Nestor, C. W., Jr.; Tucker, T. C. J. Chem. Phys. 1990, 93, 8041.

(20) Desclaux, J. P. At. Data Nucl. Data Tables 1973, 12, 311.

(21) Allen, T. L. J. Chem. Phys. 1957, 26, 1644

(22) Ionova, G. V.; Pershina, V. G. Sov. Radiochem., in press.

(23) Eichler, B. Annual Report 1993 of PSI, March 1994, 38.

(24) Ionova, G. V.; Pershina, V.; Johnson, E.; Fricke, B.; Schädel, M. J. Phys. Chem. 1992, 96, 11096

(25) Hubert-Pfalzgraf, L. G.; Postel, M.; Riess, J. G. In Comprehensive Coordination Chemistry; Wilkinson, G., Ed.; Pergamon Press: Oxford, 1978; Vol. 3, p 589.

(26) Bratsch, S. G.; Lagowski, J. J. J. Phys. Chem. 1986, 90, 307.

(27) Johnson, E.; Fricke, B. J. Phys. Chem. 1991, 95, 7082.

(28) Bratsch, S. G. J. Phys. Chem. Ref. Data 1989, 18, 1. 